\title{
The equivalent and aliovalent dopants boosting the thermoelectric properties of $\mathrm{YbMg}_{2} \mathrm{Sb}_{2}$
}

\author{
Xinxin Yang ${ }^{1}$, Yayun $\mathrm{Gu}^{1}$, Yuping $\mathrm{Li}^{1}$, Kai Guo ${ }^{1 *}$, Jiye Zhang ${ }^{{ }^{*}}$ and Jing-Tai Zhao ${ }^{1,2}$
}

\begin{abstract}
Antimony-based Zintl compounds $\mathrm{AM}_{2} \mathrm{Sb}_{2}$ $(\mathrm{A}=\mathrm{Ca}, \mathrm{Sr}, \mathrm{Ba}, \mathrm{Yb}, \mathrm{Eu} ; \mathrm{M}=\mathrm{Mg}, \mathrm{Zn}, \mathrm{Cd}, \mathrm{Mn}$ ), which enable a broad range of manipulation on electrical and thermal transport properties, are considered as an important class of thermoelectric materials. Phonon and carrier transport engineering were realized in $\mathrm{YbMg}_{2} \mathrm{Sb}_{2}$ via equivalent and aliovalent substitution of $\mathrm{Zn}$ and $\mathrm{Ag}$, respectively. The roomtemperature thermal conductivity reduces from 1.96 to $1.15 \mathrm{~W} \mathrm{~m}^{-1} \mathrm{~K}^{-1}$ for $\mathrm{YbMg}_{2-x} \mathrm{Zn}_{x} \mathrm{Sb}_{2}$ due to the mass and strain fluctuation through the formation of the absolute solid solution of $\mathrm{YbMg}_{2} \mathrm{Sb}_{2}-\mathrm{YbZn}_{2} \mathrm{Sb}_{2}$. Furthermore, the carrier concentration has been further optimized by $\mathrm{Ag}$ doping (from $0.42 \times 10^{19}$ to $7.72 \times 10^{19} \mathrm{~cm}^{-3}$ at room temperature), and thus the electrical conductivity and the power factor are enhanced effectively. The integrated aspects make the dimensionless figure of merit $(z T)$ reach 0.48 at $703 \mathrm{~K}$, which is $60 \%$ higher than the pristine $\mathrm{YbMgZnSb}_{2}$ sample.
\end{abstract}

Keywords: Zintl phase, $\mathrm{YbMg}_{2} \mathrm{Sb}_{2}$, solid solution, thermal conductivity, thermoelectric properties

\section{INTRODUCTION}

Recent global energy and environmental crisis prompt researchers to seek renewable and reliable energy resources, as well as novel strategies to utilize the waste energy in the surrounding environment. Thermoelectrics, as a clean and sustainable energy technology, enabling a direct conversion between heat and electricity based on the Seebeck and Peltier effect [1-3]. The conversion efficiency of a thermoelectric (TE) material is determined by the dimensionless figure of merit $z T=\sigma S^{2} T /\left(\kappa_{\mathrm{L}}+\kappa_{\mathrm{e}}\right)$, where $\sigma, S, T, \kappa_{\mathrm{L}}$ and $\kappa_{\mathrm{e}}$ represent the electrical conductivity, Seebeck coefficient, absolute temperature, and the lattice and electronic components of thermal conductivity $\kappa$, respectively. For a highly efficient TE mate- rial, a combination of high $\sigma$, large $S$ and low $\kappa$ are fundamentally required. However, $\sigma, S$ and $\kappa$ are strongly coupled in nature, which makes it difficult to optimize one single property without vitiating the others [4-7].

Zintl compounds, $\mathrm{AM}_{2} \mathrm{Sb}_{2}(\mathrm{~A}=\mathrm{Ca}, \mathrm{Sr}, \mathrm{Ba}, \mathrm{Yb}, \mathrm{Eu}$; $\mathrm{M}=\mathrm{Mg}, \mathrm{Zn}, \mathrm{Cd}, \mathrm{Mn})$ with a $\mathrm{CaAl}_{2} \mathrm{Si}_{2}$-type structure (space group $P 3 m 1$ ), are considered as one class of potential TE materials [8-14]. Normally, p-type $\mathrm{AM}_{2} \mathrm{Sb}_{2}$ compounds show appealing TE properties owing to their low thermal conductivity derived from the strong lattice anharmonicity and moderate electrical transport properties [9]. Enhancement of TE properties for typical p-type $\mathrm{AM}_{2} \mathrm{Sb}_{2}$ can be realized by regulating the doping at both $A$ and $M$ sites [15]. Gascoin et al. [16] reported that alloying $\mathrm{Ca}$ at the $\mathrm{Yb}$ site in $\mathrm{YbZn}_{2} \mathrm{Sb}_{2}$ would simultaneously reduce the carrier concentration and the thermal conductivity. In addition, Zevalkink et al. [17] demonstrated that the carrier concentration could be optimized through the $\mathrm{Yb}$ vacancies in $\mathrm{Yb}_{1-\delta} \mathrm{Zn}_{2} \mathrm{Sb}_{2}$. Zhang et al. [18] proposed orbital alignment to increase the band degeneracy and thus improve the power factor in 122 type Zintl compounds, which was confirmed in $\mathrm{YbCd}_{2} \mathrm{Sb}_{2}$ $-\mathrm{YbZn}_{2} \mathrm{Sb}_{2}$ system [19]. Recently, Mg-containing compounds with the same structure exhibit impressive $\mathrm{TE}$ performance including $\mathrm{Mg}_{3} \mathrm{Sb}_{2}$ [20,21], $\mathrm{Ca}_{1-x} \mathrm{Yb}_{x} \mathrm{Mg}_{2} \mathrm{Bi}_{2}$ [22] and $\mathrm{CaMg}_{2-x} \mathrm{Zn}_{x} \mathrm{Sb}_{2}$ [23], while $\mathrm{YbMg}_{2} \mathrm{Sb}_{2}$ has rarely been focused as TE material so far.

In this work, the $\mathrm{YbMg}_{2} \mathrm{Sb}_{2}-\mathrm{YbZn}_{2} \mathrm{Sb}_{2}$ system was investigated to obtain possible band alignment and suppressed thermal conductivity. Subsequently, aliovalent Ag ion doping was carried out with the aim to optimize the hole concentration for maximizing the power factor. Eventually, $\mathrm{Mg} / \mathrm{Zn}$ substitution results in the reduction of the thermal conductivity to $0.73 \mathrm{~W} \mathrm{~m}^{-1} \mathrm{~K}^{-1}$ at $573 \mathrm{~K}$, and the power factor increases to $7.58 \mathrm{~mW} \mathrm{~cm}^{-1} \mathrm{~K}^{-2}$ at $703 \mathrm{~K}$

\footnotetext{
${ }^{1}$ School of Materials Science and Engineering, Shanghai University, Shanghai 200444, China

${ }^{2}$ State Key Laboratory of Advanced Special Steel, Shanghai University, Shanghai 200444, China

* Corresponding authors (emails: kai.guo@shu.edu.cn (Guo K); jychang@shu.edu.cn (Zhang J))
} 
by doping Ag. As a result, a promising $z T$ value of 0.48 is achieved at $703 \mathrm{~K}$ in the sample of $\mathrm{Yb}(\mathrm{MgZn})_{0.992^{-}}$ $\mathrm{Ag}_{0.008} \mathrm{Sb}_{2}$.

\section{EXPERIMENTAL SECTION}

Polycrystalline $\mathrm{YbMg}_{2-x} \mathrm{Zn}_{x} \mathrm{Sb}_{2}(x=0,0.5,1,1.5,2)$ and $\mathrm{Yb}(\mathrm{MgZn})_{1-y} \mathrm{Ag}_{y} \mathrm{Sb}_{2} \quad(y=0,0.002, \quad 0.004,0.006,0.008)$ samples were synthesized by element combination reaction. The raw materials ( $\mathrm{Yb}$ 99.9\%, Mg 99.99\%, $\mathrm{Zn}$ 99.999\%, Ag 99.999\%, Sb 99.999\%) were weighed in a glove box (M. Braun, $\mathrm{O}_{2}<0.1 \mathrm{ppm}, \mathrm{H}_{2} \mathrm{O}<0.1 \mathrm{ppm}$ ) according to stoichiometric ratio, and then transferred into $\mathrm{BN}$ crucibles sealed in evacuated fused quartz tubes using a Partulab device (MRVS-3002). The reactants were slowly heated to $1273 \mathrm{~K}$ at a rate of $1 \mathrm{~K} / \mathrm{min}$ and kept for 3 days. Subsequently, these assembles were cooled to room temperature by switching off the furnace. The products were thoroughly ground and annealed at $873 \mathrm{~K}$ for another 7 days for homogenization. The as-obtained samples were sintered using a vacuum hot-press furnace at $773 \mathrm{~K}$ for $30 \mathrm{~min}$ with a pressure of $70 \mathrm{MPa}$ to obtain sufficiently dense bulk samples.

The phase purities of the as-prepared samples were examined by powder X-ray diffraction (PXRD, Rigaku, $\mathrm{Cu}$ Ka radiation, $\lambda=1.541854 \AA, 10^{\circ}<2 \theta<80^{\circ}$, step width $0.02^{\circ}$ ) at room temperature. The cell parameters were obtained by means of WinCSD software [24]. The microstructure and composition were characterized by using a scanning electron microscope (SEM; ZEISS Gemini 300, Germany) equipped with energy-dispersive X-ray spectroscopy (EDX; Oxford X-MAX, UK). The Seebeck coefficient and conductivity of the samples were measured by using a ZEM-3 apparatus (ULVAC-RIKO, Japan) under a helium atmosphere from room temperature to $703 \mathrm{~K}$. Hall effect measurements were performed under the applied magnetic field of $\sim-1$ to $1 \mathrm{~T}$ in a Hall Characterization System (LINSEIS, L79/HCS, Germany) at room temperature. The thermal conductivity was calculated according to $\kappa_{\mathrm{tot}}=C_{p} \lambda d$, where $\lambda$ is the thermal diffusivity, $C_{p}$ is the specific heat capacity, and $d$ is the density. The $\lambda$ of a disk sample with a diameter of $10 \mathrm{~mm}$ and a typical thickness of 1-2 mm was measured using laser flash diffusivity (NETZSCH, LFA457, Germany). Prior to measurement, the sample was coated with a thin graphite layer to minimize the error in material emissivity. $C_{p}$ was determined using the Dulong-Petit approximation. $d$ was measured at room temperature by applying the Archimedes method.

\section{RESULTS AND DISCUSSION}

The crystal structure of trigonal $\mathrm{YbMg}_{2} \mathrm{Sb}_{2}$ can be seen elsewhere [25]. This compound belongs to $\mathrm{CaAl}_{2} \mathrm{Si}_{2}$ -structure type [26], which is derived from a layered stacking of anionic framework and cationic layers along the $c$ axis. In the anionic framework, each $\mathrm{Mg}$ atom is connected with four $\mathrm{Sb}$ atoms to form $\mathrm{MgSb}_{4}$ tetrahedral, which are connected each other by sharing vertices and edges. Cations of $\mathrm{Yb}$ are positioned between the anionic layers to provide the electrons for satisfying the charge balance. Fig. 1a shows the PXRD patterns of the as-synthesized polycrystalline $\mathrm{YbMg}_{2-x} \mathrm{Zn}_{x} \mathrm{Sb}_{2}(x=0,0.5,1,1.5$, 2). The simulated pattern of the $\mathrm{YbZn}_{2} \mathrm{Sb}_{2}$ (ICSD No. 380377) is also provided for comparison. Apparently, the as-obtained polycrystalline samples can be indexed as $\mathrm{YbZn}_{2} \mathrm{Sb}_{2}$ phase despite obvious angle-shifts, indicating that $\mathrm{YbMg}_{2} \mathrm{Sb}_{2}$ and $\mathrm{YbZn}_{2} \mathrm{Sb}_{2}$ can form absolute solid solution. With increasing $x$, all diffraction peaks shift towards higher angle, revealing the lattice shrinkage derived from smaller atomic radius of $\mathrm{Zn}$ (Fig. 1b). As expected, the lattice parameters $a$ and $c$ both linearly decrease with the increasing $\mathrm{Zn}$ content, following the Vegard's law. Temperature dependent thermal conductivities for $\mathrm{YbMg}_{2-x} \mathrm{Zn}_{x} \mathrm{Sb}_{2}(0 \leq x \leq 2)$ are shown in Fig. 1c. The total thermal conductivity continuously decreases as temperature increases, evidencing a dominant phonon scattering by Umklapp processes. The total thermal conductivity tends to decrease first and then increase with rising $x$ at the measured temperature range (Fig. 1d), which can be understood from the alloying effect. $\mathrm{Zn}$ alloying $\mathrm{Mg}$ would induce the mass and strain fluctuation, and thus the minimum thermal conductivity can be observed with $x=1$. The electronic thermal conductivity increases with increasing $\mathrm{Zn}$ content, since $\mathrm{YbZn}_{2} \mathrm{Sb}_{2}$ has high electrical conductivity in comparison with $\mathrm{YbMg}_{2} \mathrm{Sb}_{2}$ (Fig. 1e). The lattice thermal conductivity exhibits a minimum value with $x=1$ as the total thermal conductivity (Fig. 1f). However, a high orbital degeneracy at the valence band maximum to maximum the power factor has not been achieved in this work (Supplementary information, Fig. S1), probably due to the lager composition gap.

Since the disorder of $\mathrm{Mg}$ and $\mathrm{Zn}$ would result in strong phonon scattering and enable to achieve the minimum thermal conductivity for the series samples $\mathrm{YbMg}_{2-x} \mathrm{Zn}_{x} \mathrm{Sb}_{2}$, the sample $\mathrm{YbMgZnSb}_{2}$ was further manipulated to increase the TE figure of merit $z T$, where the substitution of $\mathrm{Ag}$ at $\mathrm{Mg} / \mathrm{Zn}$ site was performed to optimize the carrier concentration. Fig. 2 displays the PXRD patterns for $\mathrm{Yb}(\mathrm{MgZn})_{1-y} \mathrm{Ag}_{y} \mathrm{Sb}_{2}(y \leq 0.008)$. All 

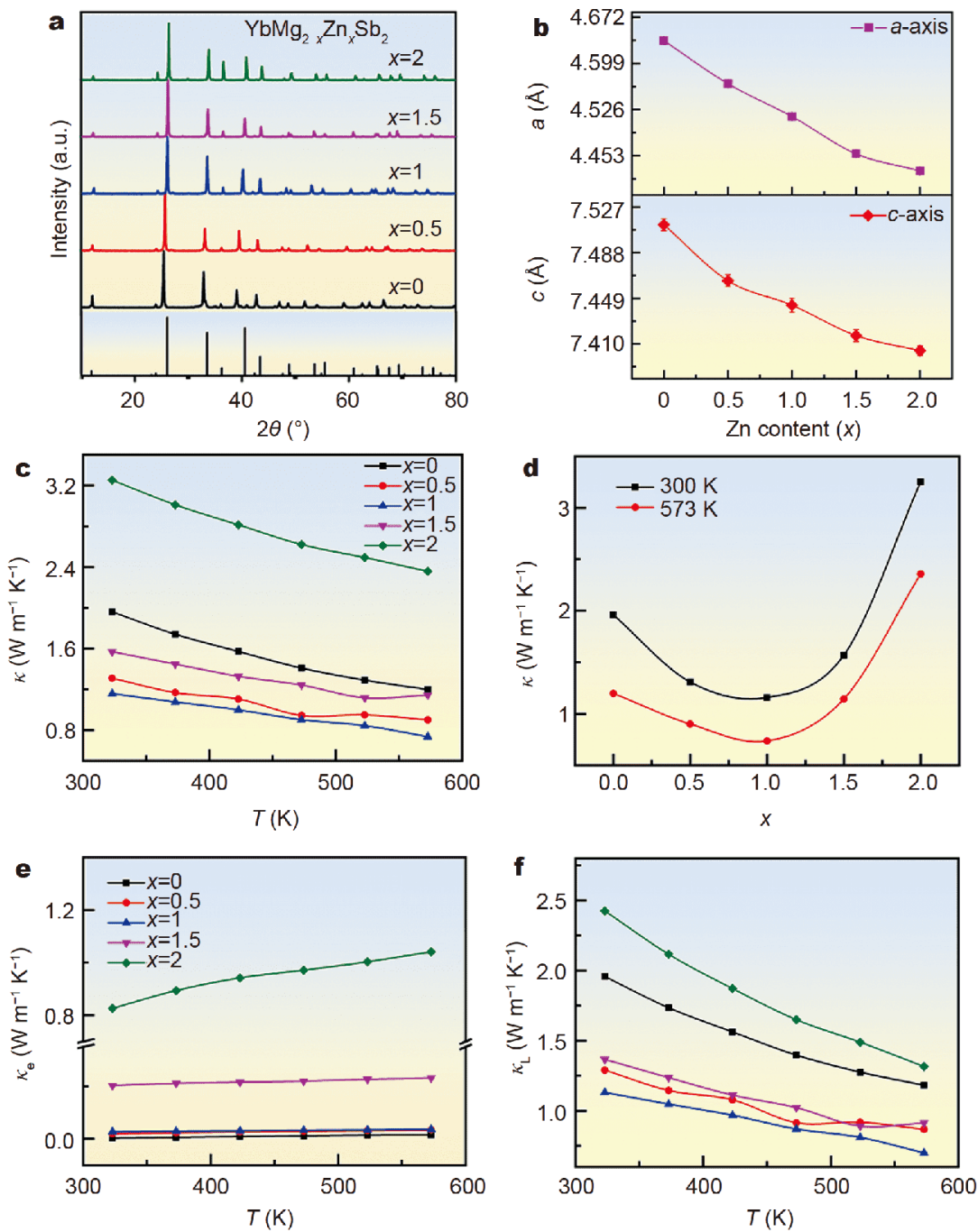

Figure 1 PXRD patterns for the $\mathrm{YbMg}_{2-x} \mathrm{Zn}_{x} \mathrm{Sb}_{2}$ samples (a), the cell parameters of the $\mathrm{YbMg}_{2-x} \mathrm{Zn}_{x} \mathrm{Sb}_{2}$ samples (b), temperature-dependent total thermal conductivity (c), composition-dependent total thermal conductivity at 300 and $573 \mathrm{~K}$ (d), electronic (e) and lattice thermal conductivity (f) for $\mathrm{YbMg}_{2-x} \mathrm{Zn}_{x} \mathrm{Sb}_{2}(0 \leq x \leq 2)$.

the main diffraction peaks can be indexed as $\mathrm{YbZn}_{2} \mathrm{Sb}_{2}$ phase as well. In comparison to $\mathrm{YbMgZnSb}_{2}$, the reflection peaks of Ag-substituted samples slightly shifted toward lower angle with increasing $x$, revealing the lattice expansion behavior. Several additional weak peaks, such as $\mathrm{Sb}_{2} \mathrm{O}_{5}$ and $\mathrm{Sb}$ (marked in Fig. 2), were observed from the traces of the impurity phase, which may be caused by oxygen impurities in the reactants and loss of $\mathrm{Mg}$ caused by volatilization during the synthesized process.

The Hall carrier concentration $\left(n_{\mathrm{H}}\right)$ for $\mathrm{Yb}(\mathrm{MgZn})_{1-y} \mathrm{Ag}_{y} \mathrm{Sb}_{2}$ (Fig. 3a) increases linearly with increasing $y(y \leq 0.008)$. Ag substitution at $\mathrm{Mg} / \mathrm{Zn}$ site can introduce more holes, and successfully rise carrier concentration from $0.42 \times 10^{19} \mathrm{~cm}^{-3}$ in pristine $\mathrm{YbMgZnSb}_{2}$ up to $7.72 \times 10^{19} \mathrm{~cm}^{-3}$ in $\mathrm{Yb}(\mathrm{MgZn})_{0.992} \mathrm{Ag}_{0.008} \mathrm{Sb}_{2}$ at room temperature. Compared with the theoretical value, the experimental carrier concentration is slightly higher due to the inherent defects of the Zintl compounds [27]. Besides, the loss of $\mathrm{Mg}$ at high temperature caused by volatilization can also lead to a higher carrier concentration. In general, the increased carrier concentration may cause a reduction of the mobility to a certain degree. However, a substantially constant mobility has been observed in Fig. 3b.

The backscattered electron images of typical $\mathrm{YbMgZnSb}_{2}$ and $\mathrm{Yb}(\mathrm{MgZn})_{0.992} \mathrm{Ag}_{0.008} \mathrm{Sb}_{2}$ samples are presented in Fig. 4a and b, respectively. Dense surface and homogeneous composition can be identified for the two 


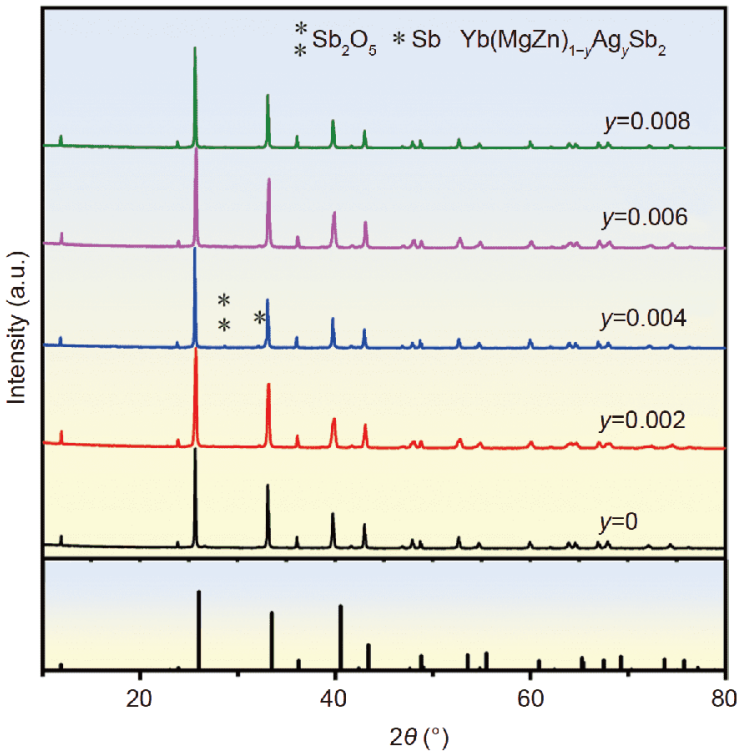

Figure 2 PXRD patterns for the $\mathrm{Yb}(\mathrm{MgZn})_{1-y} \mathrm{Ag}_{y} \mathrm{Sb}_{2}$ samples.

samples. EDX mapping was performed on the composition of the sample $\mathrm{Yb}(\mathrm{MgZn})_{0.992} \mathrm{Ag}_{0.008} \mathrm{Sb}_{2}$ (Fig. $4 \mathrm{~d}-\mathrm{g}$ ). Elements $\mathrm{Yb}, \mathrm{Mg}, \mathrm{Zn}, \mathrm{Sb}$, and $\mathrm{Ag}$ are homogeneously distributed, which is consistent with the high purity of the sample determined by PXRD analysis.

The temperature dependences of electrical conductivity, Seebeck coefficient and power factor for $\mathrm{Yb}(\mathrm{MgZn})_{1-y} \mathrm{Ag}_{y} \mathrm{Sb}_{2}$ are shown in Fig. 5a-c. The electrical conductivity of the pristine sample decreases below $528 \mathrm{~K}$ and then increases until $703 \mathrm{~K}$, which results from the intrinsic excitation behavior of semiconductor $\mathrm{YbMgZnSb}_{2}$. For the Ag-doped samples, electrical conductivity linearly decreases with increasing temperature, indicating heavily doped degenerate semiconductor behavior. Importantly, the electrical conductivity improves from $0.24 \times 10^{4}$ to $4.45 \times 10^{4} \mathrm{~S} \mathrm{~m}^{-1}$ at $303 \mathrm{~K}$ and from $0.27 \times$
$10^{4}$ to $2.65 \times 10^{4} \mathrm{~S} \mathrm{~m}^{-1}$ at $703 \mathrm{~K}$ as a result of Ag doping. The profound improvement in electrical conductivity is ascribed to the increasing carrier concentration, as shown in Fig. 3a.

The Seebeck coefficients of all the samples are positive, evidencing a p-type conduction behavior, which is consistent with the Hall coefficient measurements (Fig. 3). In addition, the Seebeck coefficient of undoped sample $\mathrm{YbMgZnSb}_{2}$ decreases at higher temperature due to the intrinsic excitation of carriers (bipolar diffusion). The peak of Seebeck coefficient curve is utilized for evaluating the band gap $\left(E_{\mathrm{g}}=2 e S_{\max } T_{\max }\right)$ value of $0.66 \mathrm{eV}$ [28]. After Ag doping, the monotonically increased Seebeck coefficient is attributed to the rising intrinsic excitation temperature, resulting in the suppression effect of heavily doped bipolar diffusion. Fig. 6 shows the Pisarenko plot at room temperature for $\mathrm{Yb}(\mathrm{MgZn})_{1-y} \mathrm{Ag}_{y} \mathrm{Sb}_{2}$ $[16,19,25,29-32]$. All the experimental data plots fall nearly perfectly on the fitting line of $m^{*}=0.7 m_{0}\left(m_{0}\right.$ is the mass of a free electron, $m^{*}=0.5 m_{0}$ and $m^{*}=1 m_{0}$ are shown for comparison), revealing that the valence band structure remains almost unchanged after $\mathrm{Ag}$ doping. The as-obtained effective masses for $\mathrm{Yb}(\mathrm{MgZn})_{1-y} \mathrm{Ag}_{y} \mathrm{Sb}_{2}$ are in good agreement with the values of other 122 Zintl phases. Although Seebeck coefficient decreases with Ag doping, there is a significant enhancement in the power factor (from 2.75 to $7.58 \mu \mathrm{W} \mathrm{cm}{ }^{-1} \mathrm{~K}^{-2}$ at $703 \mathrm{~K}$ ), which is mainly attributed to the increase in electrical conductivity.

The temperature dependences of total thermal conductivities are shown in Fig. 5d. The thermal conductivity continues to decrease linearly from 303 to $703 \mathrm{~K}$, representing a typical crystalline heat transport behavior. Despite the fact that the total thermal conductivity continuously increases with $\mathrm{Ag}$ content increasing, the highest thermal conductivity component of
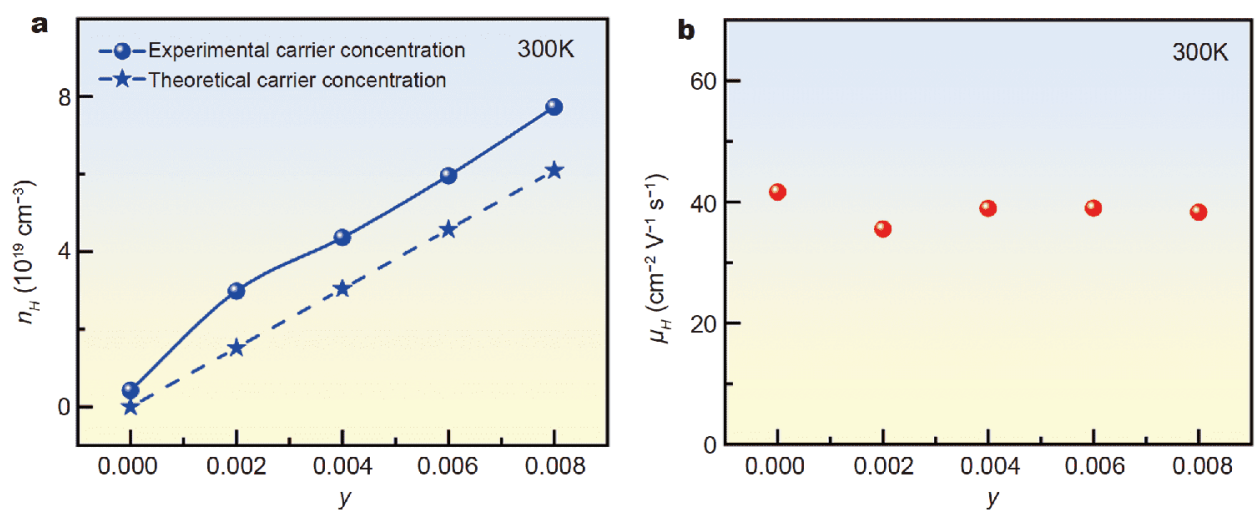

Figure 3 Room-temperature carrier concentration (a), and Hall mobility of $\mathrm{Yb}(\mathrm{MgZn})_{1-y} \mathrm{Ag}_{y} \mathrm{Sb}_{2}(0 \leq y \leq 0.008)$. 


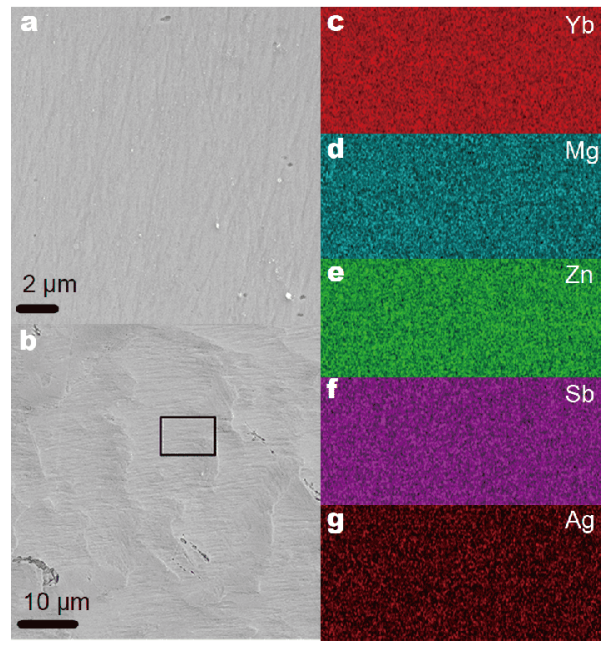

Figure $4 \mathrm{SEM}$ images of $\mathrm{YbMgZnSb}_{2}$ (a) and $\mathrm{Yb}(\mathrm{MgZn})_{0.992} \mathrm{Ag}_{0.008} \mathrm{Sb}_{2}$ (b), and EDX mapping images corresponding to the rectangular area of $\mathrm{Yb}(\mathrm{MgZn})_{0.992} \mathrm{Ag}_{0.008} \mathrm{Sb}_{2}(\mathrm{c}-\mathrm{g})$.
$\mathrm{Yb}(\mathrm{MgZn})_{0.992} \mathrm{Ag}_{0.008} \mathrm{Sb}_{2}\left(1.70 \mathrm{~W} \mathrm{~m}^{-1} \mathrm{~K}^{-1}\right)$ is still lower than that of $\mathrm{YbMg}_{2} \mathrm{Sb}_{2}\left(1.96 \mathrm{~W} \mathrm{~m}^{-1} \mathrm{~K}^{-1}\right)$ and $\mathrm{YbZn}_{2} \mathrm{Sb}_{2}$ $\left(3.25 \mathrm{~W} \mathrm{~m}^{-1} \mathrm{~K}^{-1}\right)$ at $303 \mathrm{~K}$. The electrical thermal conductivity increases continuously with increasing $y$ (Fig. 5e), which is calculated using the Wiedemann-Franz law ( $\kappa_{\mathrm{e}}=L \sigma T, L$ is the Lorenz factor determined from the classic single parabolic band (SPB) model with acoustic scattering). The increase in total thermal conductivity is mainly due to the increase of electronic thermal conductivity. The lattice thermal conductivity gradually decreases with the increasing temperature, basically conforming to the function of $T^{-1}$, revealing a dominant phonon scattering at higher temperature (Fig. 5f). Simultaneously, the lattice thermal conductivity decreases slightly as rising $x$ due to point defect scattering attributed to the size and the atom mass fluctuation among $\mathrm{Mg}$, Zn and Ag.

Although the Ag-doping slightly increases the thermal conductivity, it contributes more to the electrical prop-
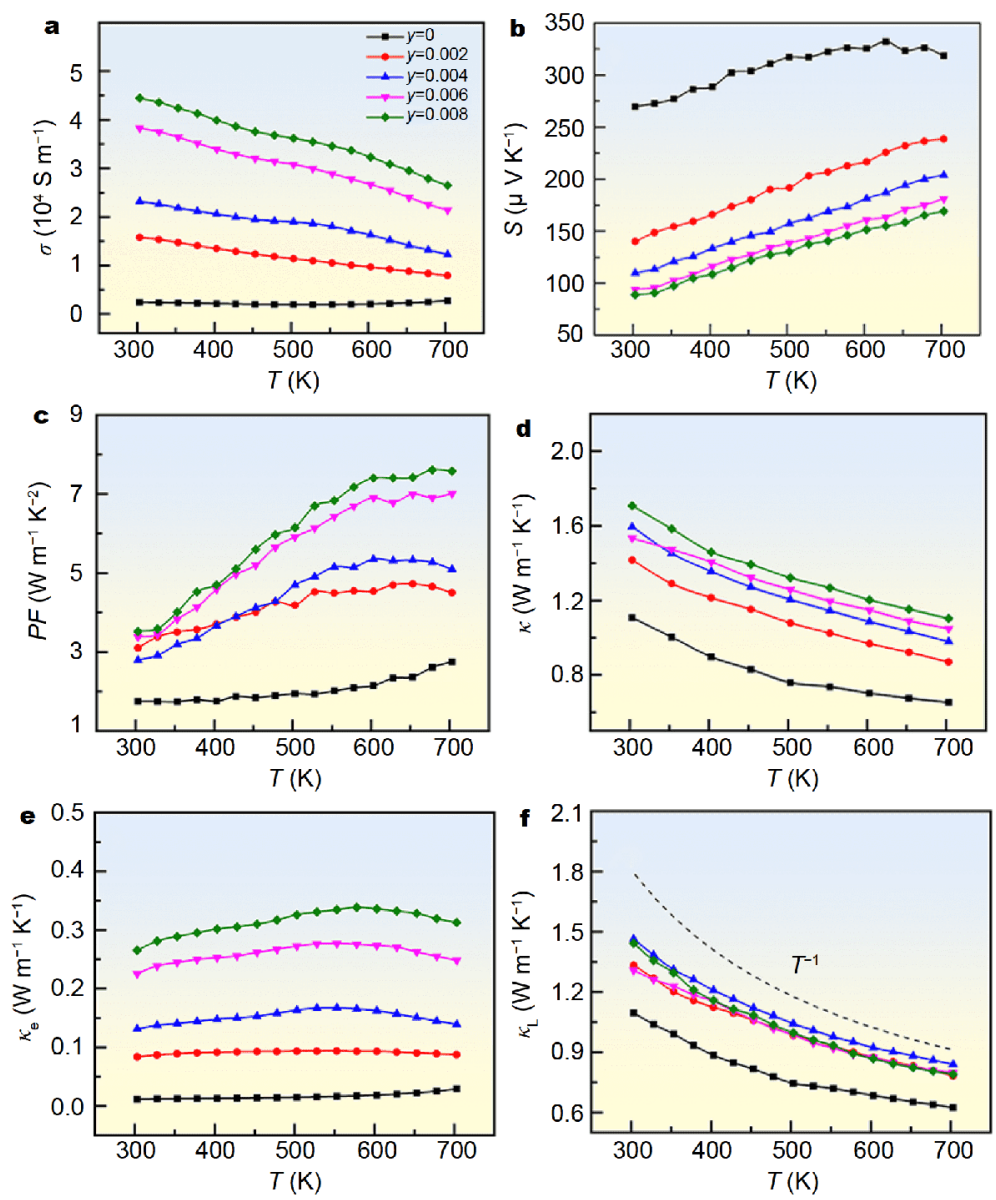

Figure 5 Temperature dependence of electrical conductivity (a), Seebeck coefficient (b), power factor (c), total (d), electrical (e) and lattice thermal conductivity (f) for $\mathrm{Yb}(\mathrm{MgZn})_{1-y} \mathrm{Ag}_{y} \mathrm{Sb}_{2}$. 


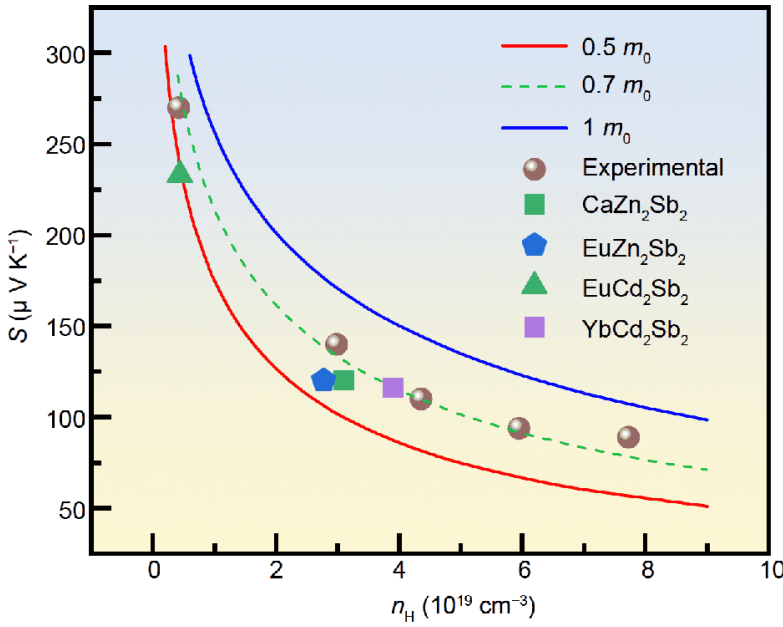

Figure 6 Seebeck coefficient as function of Hall carrier concentration for $\mathrm{Yb}\left(\mathrm{Mg}_{1-x} \mathrm{Zn}_{x}\right)_{1-y} \mathrm{Ag}_{y} \mathrm{Sb}_{2}$. The corresponding data for $\mathrm{CaZn}_{2} \mathrm{Sb}_{2}$ $[16,25], \mathrm{EuZn}_{2} \mathrm{Sb}_{2}[9,29,30], \mathrm{EuCd}_{2} \mathrm{Sb}_{2}[31]$ and $\mathrm{YbCd}_{2} \mathrm{Sb}_{2}[19,32]$ are provided for comparison.

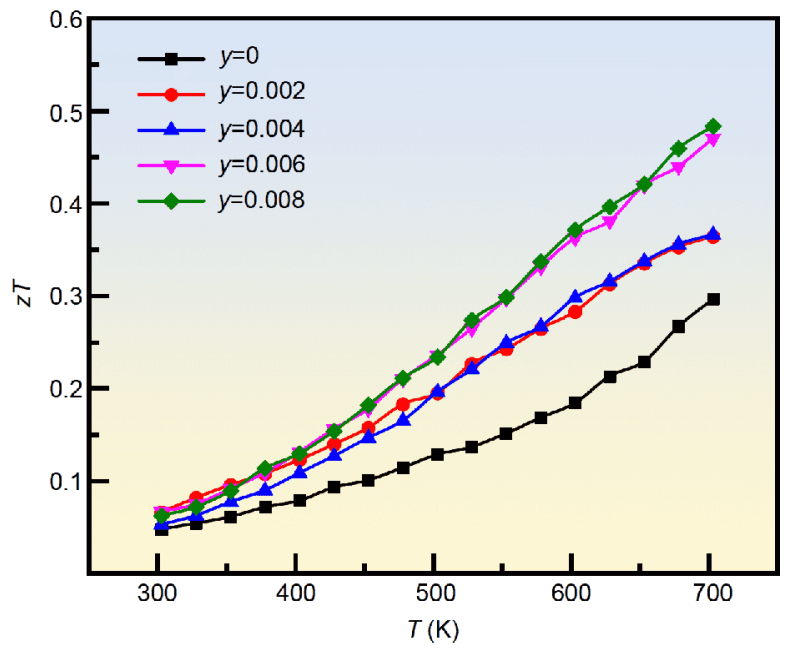

Figure 7 Temperature dependence of figure of merit $z T$ for $\mathrm{Yb}(\mathrm{MgZn})_{1-y} \mathrm{Ag}_{\mathrm{g}} \mathrm{Sb}_{2}$.

erties and eventually reaches a maximum $z T=0.48$ at $703 \mathrm{~K}$ for $\mathrm{Yb}(\mathrm{MgZn})_{0.992} \mathrm{Ag}_{0.008} \mathrm{Sb}_{2}$ (Fig. 7), which has an obvious improvement $60 \%$ higher than $\mathrm{Yb}(\mathrm{MgZn}) \mathrm{Sb}_{2}$ $(z T=0.3)$. From the trend of the curve, even higher $z T$ are expected to be further achieved above $703 \mathrm{~K}$.

\section{CONCLUSIONS}

Polycrystalline $\mathrm{Yb}\left(\mathrm{Mg}_{1-x} \mathrm{Zn}_{x}\right)_{1-y} \mathrm{Ag}_{y} \mathrm{Sb}_{2}(0 \leq x \leq 2,0 \leq y \leq$ 0.008 ) samples were prepared by the traditional solidstate reaction followed by vacuum hot-pressing sintering technology. The room-temperature thermal conductivity is reduced from 1.96 to $1.15 \mathrm{~W} \mathrm{~m}^{-1} \mathrm{~K}^{-1}$ by solid solution of $\mathrm{YbMg}_{2} \mathrm{Sb}_{2}$ and $\mathrm{YbZn}_{2} \mathrm{Sb}_{2}$. Furthermore, the carrier concentration is optimized (from $0.42 \times 10^{19}$ to $7.72 \times$ $10^{19} \mathrm{~cm}^{-3}$ at room temperature) by the doping of $\mathrm{Ag}$, thereby improving the electrical conductivity and the power factor. The combination of the two aspects makes $z T$ reach 0.48 at $703 \mathrm{~K}$, which is $60 \%$ higher than that of the pure sample $\mathrm{YbMgZnSb}_{2}$. This work gives a good understanding of the TE compound $\mathrm{YbMg}_{2} \mathrm{Sb}_{2}$, and also provides a valuable idea for improving the TE properties of $\mathrm{YbM}_{2} \mathrm{Sb}_{2}$ solid solution.

Received 19 July 2019; accepted 25 September 2019;

published online 7 November 2019

1 Tritt TM. Thermoelectric materials: Holey and unholey semiconductors. Science, 1999, 283: 804-805

2 Zhang X, Zhao LD. Thermoelectric materials: Energy conversion between heat and electricity. J Materiomics, 2015, 1: 92-105

3 DiSalvo FJ. Thermoelectric cooling and power generation. Science, 1999, 285: 703-706

4 Zhang Q, Sun Y, Xu W, et al. Organic thermoelectric materials: Emerging green energy materials converting heat to electricity directly and efficiently. Adv Mater, 2014, 26: 6829-6851

5 Toberer ES, May AF, Snyder GJ. Zintl chemistry for designing high efficiency thermoelectric materials. Chem Mater, 2010, 22: 624634

6 Dresselhaus M, Chen G, Tang M, et al. New directions for lowdimensional thermoelectric materials. Adv Mater, 2017, 19: 10431053

7 Wei TR, Qin Y, Deng T, et al. Copper chalcogenide thermoelectric materials. Sci China Mater, 2019, 62: 8-24

8 Cao QG, Zhang $\mathrm{H}$, Tang MB, et al. Zintl phase $\mathrm{Yb}_{1-x} \mathrm{Ca}_{x} \mathrm{Cd}_{2} \mathrm{Sb}_{2}$ with tunable thermoelectric properties induced by cation substitution. J Appl Phys, 2010, 107: 053714

9 Guo K, Cao Q, Zhao J. Zintl phase compounds $A M_{2} \mathrm{Sb}_{2}(A=\mathrm{Ca}$, Sr, $\mathrm{Ba}, \mathrm{Eu}, \mathrm{Yb} ; \mathrm{M}=\mathrm{Zn}, \mathrm{Cd}$ ) and their substitution variants: A class of potential thermoelectric materials. J Rare Earths, 2013, 31: 10291038

10 Wang $\mathrm{X}, \mathrm{Li} \mathrm{W}$, Wang $\mathrm{C}$, et al. Single parabolic band transport in ptype $\mathrm{EuZn}_{2} \mathrm{Sb}_{2}$ thermoelectrics. J Mater Chem A, 2017, 5: 2418524192

11 Toberer ES, May AF, Melot BC, et al. Electronic structure and transport in thermoelectric compounds $A \mathrm{Zn}_{2} \mathrm{Sb}_{2}(A=\mathrm{Sr}, \mathrm{Ca}, \mathrm{Yb}$, Eu). Dalton Trans, 2010, 39: 1046-1054

12 Guo K, Cao QG, Feng XJ, et al. Enhanced thermoelectric figure of merit of Zintl phase $\mathrm{YbCd}_{2-x} \mathrm{Mn}_{x} \mathrm{Sb}_{2}$ by chemical substitution. Eur J Inorg Chem, 2011, 2011(26): 4043-4048

13 Shuai J, Mao J, Song S, et al. Recent progress and future challenges on thermoelectric Zintl materials. Mater Today Phys, 2017, 1: 7495

14 Shuai J, Geng H, Lan Y, et al. Higher thermoelectric performance of Zintl phases $\left(\mathrm{Eu}_{0.5} \mathrm{Yb}_{0.5}\right)_{1-x} \mathrm{Ca}_{x} \mathrm{Mg}_{2} \mathrm{Bi}_{2}$ by band engineering and strain fluctuation. Proc Natl Acad Sci USA, 2016, 113: E4125E4132

15 Takagiwa Y, Sato Y, Zevalkink A, et al. Thermoelectric properties of EuZn $\mathrm{Sb}_{2}$ Zintl compounds: $z T$ enhancement through $\mathrm{Yb}$ substitution for Eu. J Alloys Compd, 2017, 703: 73-79

16 Gascoin F, Ottensmann S, Stark D, et al. Zintl phases as thermo- 
electric materials: Tuned transport properties of the compounds $\mathrm{Ca}_{x} \mathrm{Yb}_{1-x} \mathrm{Zn}_{2} \mathrm{Sb}_{2}$. Adv Funct Mater, 2005, 15: 1860-1864

17 Zevalkink A, Zeier WG, Cheng E, et al. Nonstoichiometry in the Zintl Phase $\mathrm{Yb}_{1-\delta} \mathrm{Zn}_{2} \mathrm{Sb}_{2}$ as a route to thermoelectric optimization. Chem Mater, 2014, 26: 5710-5717

18 Zhang J, Song L, Pedersen SH, et al. Discovery of high-performance low-cost n-type $\mathrm{Mg}_{3} \mathrm{Sb}_{2}$-based thermoelectric materials with multi-valley conduction bands. Nat Commun, 2017, 8: 13901

19 Wang XJ, Tang MB, Chen HH, et al. Synthesis and high thermoelectric efficiency of Zintl phase $\mathrm{YbCd}_{2-x} \mathrm{Zn}_{x} \mathrm{Sb}_{2}$. Appl Phys Lett, 2009, 94: 092106

20 Ohno S, Imasato K, Anand S, et al. Phase boundary mapping to obtain n-type $\mathrm{Mg}_{3} \mathrm{Sb}_{2}$-based thermoelectrics. Joule, 2018, 2: 141154

21 Song L, Zhang J, Iversen BB. Simultaneous improvement of power factor and thermal conductivity via $\mathrm{Ag}$ doping in p-type $\mathrm{Mg}_{3} \mathrm{Sb}_{2}$ thermoelectric materials. J Mater Chem A, 2017, 5: 4932-4939

22 Shuai J, Liu Z, Kim HS, et al. Thermoelectric properties of Bi-based Zintl compounds $\mathrm{Ca}_{1-x} \mathrm{Yb}_{x} \mathrm{Mg}_{2} \mathrm{Bi}_{2}$. J Mater Chem A, 2016, 4: 43124320

23 Wood M, Aydemir U, Ohno S, et al. Observation of valence band crossing: The thermoelectric properties of $\mathrm{CaZn}_{2} \mathrm{Sb}_{2}-\mathrm{CaMg}_{2} \mathrm{Sb}_{2}$ solid solution. J Mater Chem A, 2018, 6: 9437-9444

24 Akselrud L, Grin Y. WinCSD: Software package for crystallographic calculations (Version 4). J Appl Crystlogr, 2014, 47: 803805

25 Mewis A. $A B_{2} X_{2}$-Verbindungen im $\mathrm{CaAl}_{2} \mathrm{Si}_{2}$-Typ, IV[1] Zur Struktur der Verbindungen $\mathrm{CaZn}_{2} \mathrm{Sb}_{2}, \mathrm{CaCd}_{2} \mathrm{Sb}_{2}, \mathrm{SrZn}_{2} \mathrm{Sb}_{2}$ und $\mathrm{SrCd}_{2} \mathrm{Sb}_{2} / A B_{2} X_{2}$ Compounds with the $\mathrm{CaAl}_{2} \mathrm{Si}_{2}$ Structure, IV[1] The Crystal Structure of $\mathrm{CaZn}_{2} \mathrm{Sb}_{2}, \mathrm{CaCd}_{2} \mathrm{Sb}_{2}, \mathrm{SrZn}_{2} \mathrm{Sb}_{2}$, and $\mathrm{SrCd}_{2} \mathrm{Sb}_{2}$. In: Zeitschrift für Naturforschung B, 1978, 382

26 Burdett JK, Miller GJ. Fragment formalism in main-group solids: Applications to aluminum boride $\left(\mathrm{AlB}_{2}\right)$, calcium aluminum silicide $\left(\mathrm{CaAl}_{2} \mathrm{Si}_{2}\right)$, barium-aluminum $\left(\mathrm{BaAl}_{4}\right)$, and related materials. Chem Mater, 1990, 2: 12-26

27 Pomrehn GS, Zevalkink A, Zeier WG, et al. Defect-controlled electronic properties in $A \mathrm{Zn}_{2} \mathrm{Sb}_{2}$ zintl phases. Angew Chem Int Ed, 2014, 53: 3422-3426

28 Goldsmid HJ, Sharp JW. Estimation of the thermal band gap of a semiconductor from seebeck measurements. J Elec Materi, 1999, 28: $869-872$

29 Klüfers $\mathrm{P}$, Neumann $\mathrm{H}$, Mewis A, et al. $A B_{2} X_{2}$-Verbindungen im $\mathrm{CaAl}_{2} \mathrm{Si}_{2}$-Typ, VIII[1]/AB $\mathrm{X}_{2}$ Compounds with the $\mathrm{CaAl}_{2} \mathrm{Si}_{2}$ Structure, VIII[1]. In: Zeitschrift für Naturforschung B, 1980, 1317

30 Zhang H, Zhao JT, Grin Y, et al. A new type of thermoelectric material, $\mathrm{EuZn}_{2} \mathrm{Sb}_{2}$. J Chem Phys, 2008, 129: 164713

31 Zheng L, Li W, Wang X, et al. Alloying for orbital alignment enables thermoelectric enhancement of $\mathrm{EuCd}_{2} \mathrm{Sb}_{2}$. J Mater Chem A, 2019, 7: 12773-12778

32 Artmann A, Mewis A, Roepke M, et al. $A M_{2} X_{2}$-verbindungen mit $\mathrm{CaAl}_{2} \mathrm{Si}_{2}$-struktur. XI. Struktur und eigenschaften der verbindungen $A_{C_{2}} X_{2}$ (A: Eu, Yb; X: P, As, Sb). Z Anorg Allg Chem, 1996, 622: $679-682$

Acknowledgements This work was supported by the National Key Research and Development Program of China (2018YFA0702100), the National Natural Science Foundation of China (21771123), the Programme of Introducing Talents of Discipline to Universities (D16002), the Science and Technology Commission of Shanghai Municipality (15DZ2260300), and Key Laboratory of Optoelectronic Materials
Chemistry and Physics, Chinese Academy of Sciences (2008DP173016).

Author contributions Yang $\mathrm{X}$ wrote this manuscript with the support from Li Y and Zhao J-T. Guo K designed the experiments and analyzed the data. Gu Y performed the experiments. Zhang J did the property measurements. All authors contributed to the general discussion.

Conflict of interest The authors declare that they have no conflict of interest.

Supplementary information Supporting data are available in the online version of the paper.

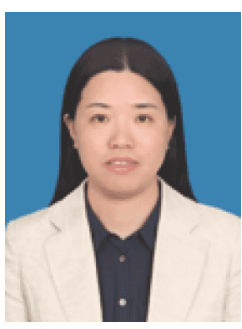

Xinxin Yang received her Bachelor's degree from Central South University in 1999, and PhD degree from Shanghai Institute of Ceramics, Chinese Academy of Sciences under the supervisor of Prof. Jing-Tai Zhao in 2013. Her research interest focuses on the crystal structure and physical properties of intermetallic compounds.

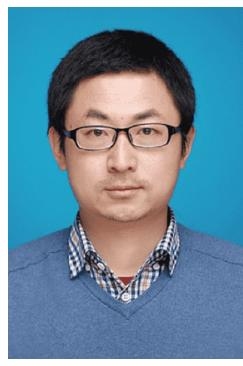

Kai Guo received his Bachelor's degree from Huazhong University of Science and Technology in 2006, and $\mathrm{PhD}$ from Shanghai Institute of Ceramics, Chinese Academy of Sciences under the supervision of Prof. Jing-Tai Zhao in 2011. $\mathrm{He}$ worked on high-pressure synthesis as a postdoctor in Max-Planck Institute for Chemical Physics of solids. His research interest focuses on the structure-property relationship of thermoelectric materials.

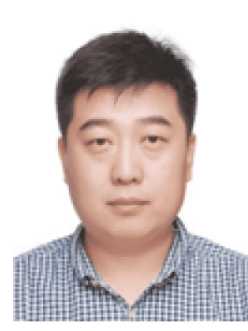

Jiye Zhang obtained his $\mathrm{PhD}$ degree from the Institute of Physics, Chinese Academy of Sciences in 2008. Now, he is an associate professor of the School of Materials Science and Engineering, Shanghai University. His main research interests focus on exotic thermal and electrical transport behaviors in thermoelectric materials from the interplay among spin, charge and lattice of degrees of freedom.

\section{通过等价和异价元素掺杂促进 $\mathrm{YbMg}_{2} \mathrm{Sb}_{2}$ 热电性能 提升}

杨昕昕 ${ }^{1}$, 顾亚运 ${ }^{1}$, 李玉瓶 ${ }^{1}$, 郭凯 ${ }^{1^{*}}$, 张继业 ${ }^{1^{*}}$, 赵景泰 ${ }^{1,2}$

摘要 由于其电热输运性能便于调控, 锑基Zintl相化合物 $\mathrm{AM}_{2} \mathrm{Sb}_{2}$ $(\mathrm{A}=\mathrm{Ca}, \mathrm{Sr}, \mathrm{Ba}, \mathrm{Yb}, \mathrm{Eu} ; \mathrm{M}=\mathrm{Mg}, \mathrm{Zn}, \mathrm{Cd}, \mathrm{Mn})$ 被认为是一类重要的 热电材料. 本文通过在 $\mathrm{YbMg}_{2} \mathrm{Sb}_{2}$ 中掺入等价的元素 $\mathrm{Zn}$ 和异价元素 $\mathrm{Ag}$, 实现了声子和载流子的输运性能优化. 首先, 体系 $\mathrm{YbMg}_{2-x^{-}}$ $\mathrm{Zn}_{x} \mathrm{Sb}_{2}$ 室温热导率从 $1.96 \mathrm{~W} \mathrm{~m}^{-1} \mathrm{~K}^{-1}$ 降低至 $1.15 \mathrm{~W} \mathrm{~m}^{-1} \mathrm{~K}^{-1}$, 这是 由于形成 $\mathrm{YbMg}_{2} \mathrm{Sb}_{2}-\mathrm{YbZn}_{2} \mathrm{Sb}_{2}$ 的固溶体带来的合金化散射效应. 其 次, 掺杂 $\mathrm{Ag}$ 可以增加载流子浓度, 其数值在室温下从 $0.42 \times 10^{19} \mathrm{~cm}^{-3}$ 提升至7.72 $\times 10^{19} \mathrm{~cm}^{-3}$, 从而有效地提高了电导率和功率因子. 通过 综合两方面的协同效应使得体系 $z T$ 在 $703 \mathrm{~K}$ 时达到 0.48 , 比纯样品 $\mathrm{YbMgZnSb}_{2}$ 高 $60 \%$. 